\title{
Nitrogen Fixation: the Growth of a New British Industry. ${ }^{1}$
}

$\mathrm{H}$ AVING now in general terms surveyed the raison d'être and the state of development of this modern industry, we will consider the circumstances of its establishment in Great Britain, and the remarkable vigour of its growth under the direction of the Imperial Chemical Industries, Ltd.

The War had been in progress for some time before the importance of the catalytic process for the production of ammonia, as a preliminary to its catalytic oxidation to nitric acid, was sufficiently realised outside scientific circles. In due course, however, the Nitrogen Products Committee was established and, whilst recommending the cyanamide process as being the only possible process agreeing to take over the assets and liabilities of the concern early in 1920, the technical staff, which had meanwhile been kept actively in being, moving to Billingham in June of that year; at the same time the subsidiary company, Synthetic Ammonia and Nitrates, Ltd., commenced its official existence. Now, of course, both of these companies form part of Imperial Chemical Industries, Ltd.

The whole problem had to be studied afresh from the beginning, and the first move was the establishment of a research laboratory, which, incidentally, cost some $£ 80,000$ (see Fig. 1). Simultaneously, a small plant was erected at the works of the Castner Kellner Co., Ltd., at Runcorn, where pure ammonia

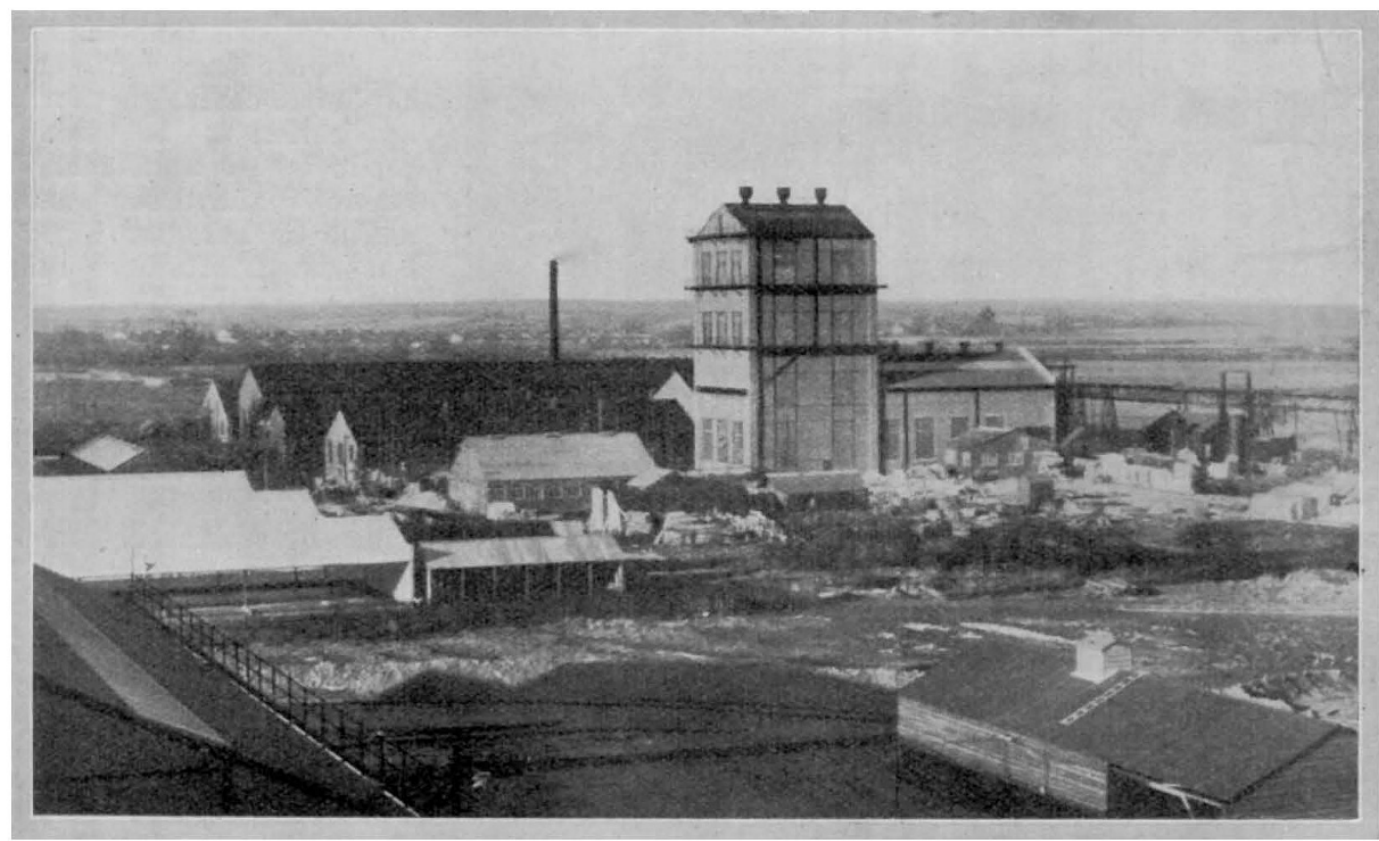

FIG. 1.-The laboratories of Synthetic Ammonia and Nitrates, Ltd., Billingham.

concerning which sufficient information was then available, organised research in other appropriate directions. Much careful investigation was carried out and valuable results were accumulated, although at that time naturally not published. As a result of the work of Greenwood, Rideal, Partington, and others at University College, London, the Department of Explosives Supply decided in 1917 to erect a plant at Billingham, near Stockton-onTees, for the purpose of producing ammonium nitrate by Haber's process; a grant of five million pounds being made to finance the project. However, when about a quarter of this sum had been spent, it was found that the dimensions of the task were so great as to prevent its completion in time to be of military value. The whole scheme was reexamined in 1919, and considered to bear promise of fruition as a peace-time industry. Negotiations led finally to Messrs. Brunner, Mond, and Co., Ltd.,

Continued from p. 20.

No. 3089, VoL. 123] has been made continuously since June 1921 in increasing quantities. The hydrogen employed was a waste product in the electrolysis of brine for the manufacture of caustic soda and chlorine. The experience so gained was found to justify the erection of a complete plant at Billingham, using as much as possible of the old material, and designed for the production of 30 tons of ammonia per day; so rapidly and enormously has the factory grown (see Figs. 2 and 3 ) that the present capacity of 70,000 tons of fixed nitrogen per annum will, in 1929 or 1930, have been increased to 170,000 tons annually of fixed nitrogen, all of which, except for a comparatively small quantity employed in refrigeration, is used for the production of compounds of importance in agriculture, the dye industry, artificial silk industry, etc. In the meantime the village has become a small town, where 6000 employees will, in a couple of years, have been joined by a further 9000 ; where plans for 500 
houses, an entertainment hall, and a pavilion have been approved, and 500 more houses are in contemplation; where new playing fields and tennis courts are being provided; where, in short, a new industrial community is being established.

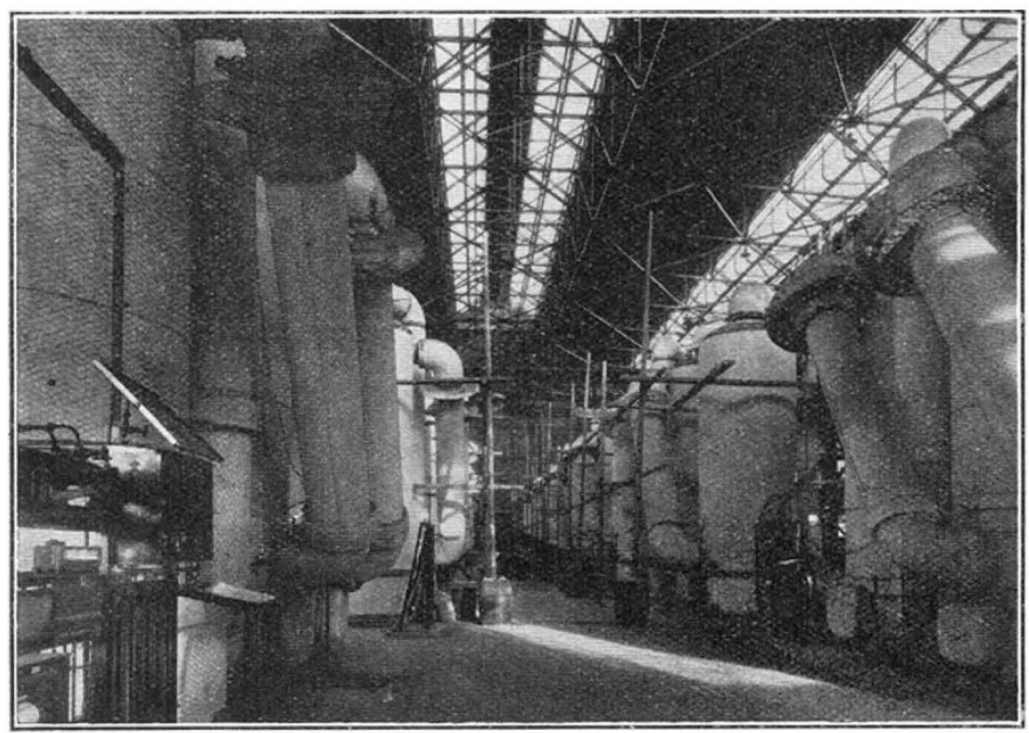

FIG. 2.-New hydrogen plant.

The technique of the production of ammonia by the Haber-Bosch process is essentially the technique of high-pressure reactions. It was immediately found that the ordinary types of plant, such as were then obtainable, were entirely inadequate for the needs of the new processes, so that the company was compelled to pioneer in this direction also, carving out its own path and learning during its progress. That the task of design and manufacture of such highpressure apparatus is being satisfactorily accomplished is evident from Lieut.-Col. Pollitt's statement that the plant is in many respects simpler to operate and easier to maintain than lowpressure plant (see Fig. 4). The process, in outline, is as follows. Air and steam are together passed through incandescent coke in gas generators which provide for the efficient conservation of heat and full automatic control. From the product, which consists of hydrogen, nitrogen, carbon monoxide, and carbon dioxide, the carbon monoxide is removed by catalytic interaction with steam, and the carbon dioxide by treatment with water under pressure; the hydrogen and nitrogen in the proportion by volume of $3: 1$ are then highly compressed and subjected to the action of the catalyst in converters the working temperature of which is $500^{\circ} \mathrm{C}$. The ammonia is dissolved in water and combined with some of the carbon dioxide previously removed. In order to avoid the use of sulphuric acid in converting this ammonia into sulphate, the more economical process of causing the ammonium carbonate to react, in aqueous solution, with anhydrite (calcium sulphate) is employed. Not only is the material ready at hand-there is a large deposit of anhydrite some $700 \mathrm{ft}$. below the site of the works-but also the calcium carbonate which is precipitated in the reaction is of industrial value, being produced in a form suitable for the manufacture of Portland cement, or for combination with ammonium nitrate to produce a new fertiliser known as ' nitro-chalk,' or for direct application to the land. Other products are ammonium bicarbonate, anhydrous ammonia, and nitric acid (see Fig. 5), the last-named substance being, of course, produced by catalytic oxidation of the ammonia.

Naturally, the experience gained in high-pressure technique is being simultaneously applied to reactions other than that from which it originated, such, for example, as the production of methyl alcohol from water gas by a catalytic process. It may eventually be possible to manufacture higher

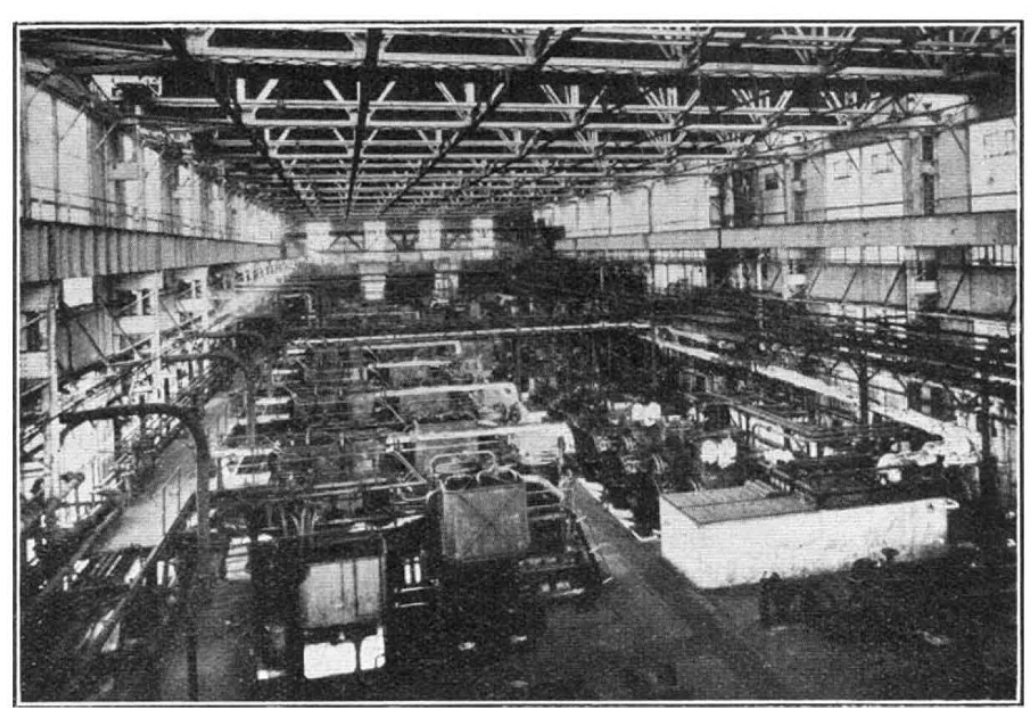

FIG. 3.-Ammonia plant.

alcohols by means of this type of procedure, and the possibility of the conversion of methane, obtained by the distillation of coal, into acetylene and hence into numerous organic substances, is not to be ignored. These developments have necessitated laboratory and research staff extensions in No. 3089, VoL. 123] 
rapid succession, for although the routine work has naturally increased, it remains a comparatively small fraction of the whole. The growth of an efficient instrument service, whereby so many different kinds of operation can be recorded and often controlled, whilst bringing in its train an important group of physical problems, simplifies in no small measure the task of accurate and knowledgeable control, and frequently indicates directions in which improvements are desirable.

It will be seen that the trend of industrial chemistry evidenced by the work at Billingham under the direction of Imperial Chemical Industries, Ltd., is no less than the replacement of products obtained from agricultural operations by products obtained from coal. Such a policy is in consonance with an era of mechanical transport, and it is peculiarly applicable to the British Empire. Although, as has been indicated, in any future war the fixed nitrogen industry might well find itself the base on which successful military action rested, and Billingham, Newcastle, and Birmingham might typify the pivot around which policy might revolve, it must emphatically be realised that the existence and development of this industry is a requirement,

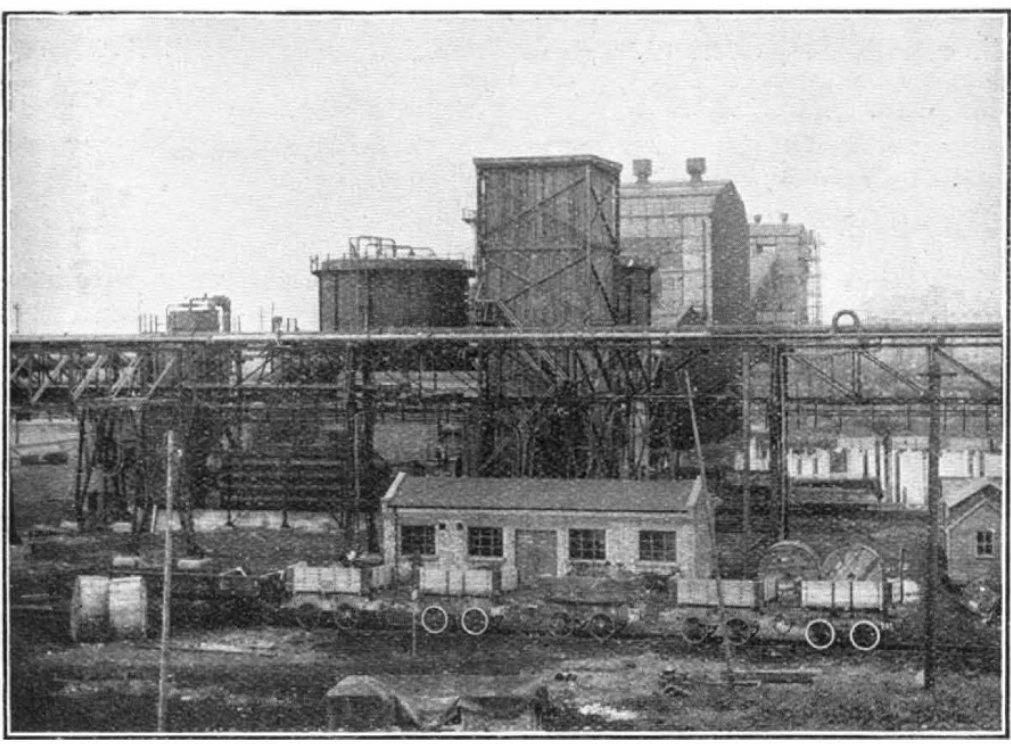

FIG. 5.-Nitric acid plant.

and an urgent one, of times of peace. It tends to bring comforts of modern civilisation within the reach of greater numbers, and its aim is to make two blades of grass grow where one grew before.

How far it succeeds in this latter aim can be judged, for example, from statistics supplied by
Dr. H. J. Page, head of the Nitram Experiment Station, which is operated by Nitram, Ltd., an associated company dealing with the application of the products manufactured by Synthetic Ammonia and Nitrates, Ltd. Dr. Page shows that

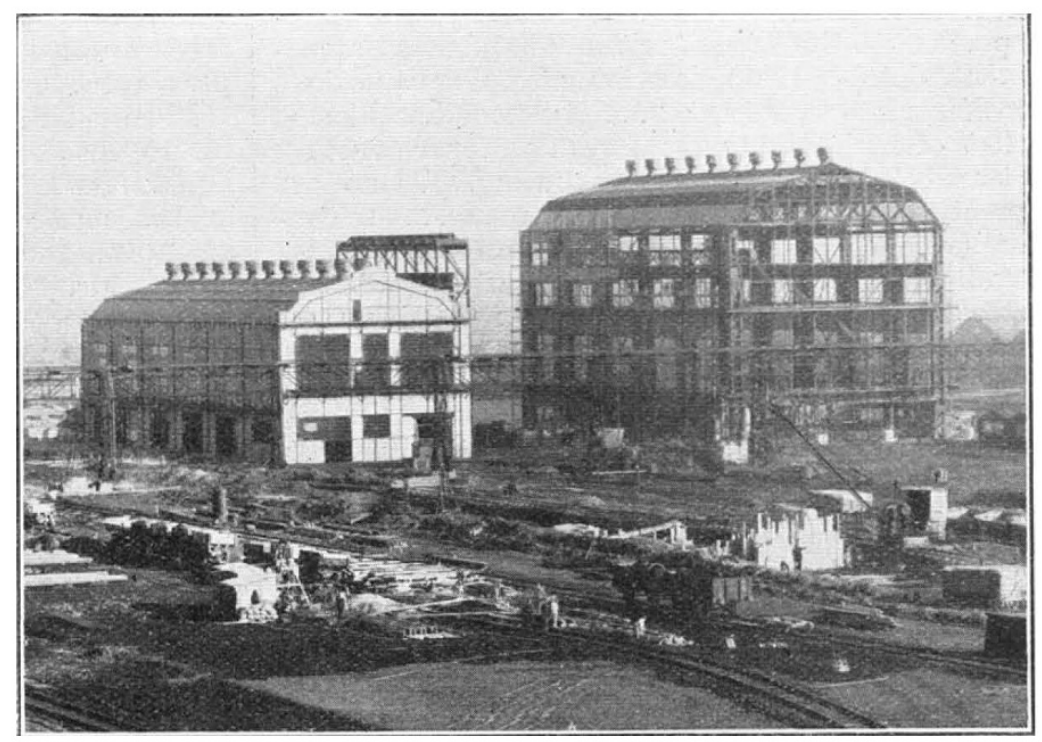

Fig. 4.-Buildings for new high pressure plant.

by giving grassland at eighty centres in the British Isles a basal dressing of phosphate and potash, and then successive dressings of ammonium sulphate at short intervals, the productivity is so increased that instead of two acres, only 0.72 of an acre is necessary to feed one cow. As Sir Daniel Hall has pointed out, British farmers can now modify the traditional practice of understocking. The British farmer, however, being somewhat conservative, and preferring usually to see before he believes, a 'Nitram' demonstration van tours the country in order to explain the new uses of sulphate of ammonia and nitro-chalk; the van carries instructional leaflets, specimens of the products of Synthetic Ammonia and Nitrates, Ltd., specimen turves, etc. A statement made at the second International Nitrogen Conference in the spring of last year by Sir Frederick Keeble is also worth recording, indicating as it does the margin between practice and possibility which is available for exploration and exploitation. He remarked that at a recent potato-growing competition organised by Nitram, Ltd., in Northern Ireland, the winner raised a crop of 28 tons to the acre, and no competitor raised less than 15 tons to the acre, whilst the average in England is less than seven tons per

No. 3089, VoL. 123] 
acre. Parenthetically, it must be noted that although fixed nitrogen is of such great importance in fertiliser practice, soil requirements of other elements have also to be provided. Examples of the influence on crop yield of systematic fertilisation might be multiplied. So also might examples of neglect to profit thereby. For example, a correspondent to the Times (British West Africa Supplement, October 1928), describing farming conditions in Sierra Leone, writes : ". . The second problem is that of maintaining the fertility of permanently cleared land by suitable manuring. There are practically no horses and very few cattle.... In consequence there is no form of farmyard manure available, and the average native farmer sets more store on putting up some sort of ' ju-ju' to protect and encourage his crops than on considering the purchase of artificial manures." Ju-jus, let it be observed, are of divers kinds.

The growth of the fixed nitrogen industry has lowered the prices, in terms of goods, of all nitrogenous fertilisers, and of phosphates and potash also, but we still lack sufficient accurate and co-ordinated scientific knowledge of the extent of the benefits which may be ours; of the factors determining soil fertility and climate; of the state of combination, interactions, proportions, and variations in the elements concerned. At Rotham. sted it has been realised that although an enormous mass of data was being accumulated, it was not being employed to the best advantage by older methods of examination, and in consequence modern statistical methods have been applied. These methods have opened up a new line of study - the study of the influence of nutrients on the reaction of the plant to environmental conditions, that is, the influence of soil and climatic conditions on the effectiveness of fertilisers. Those in the best position to judge have declared that, if the general character of a season could be predicted, appropriate manurial schemes could be recommended, or tables of expectancy of crop yield could be constructed for the guidance of insurance companies willing to insure farmers using recognised fertiliser mixtures against getting less than an agreed yield per acre.

Finally, we must not, in contemplation of a rosy future, lose sight of the realities of the present. Unless new knowledge is acquired, unless education in the modern use of nitrogenous fertilisers is advanced, the danger of overproduction may be great. Mr. F. C. O. Speyer, the general manager and a director of Nitram, Ltd., estimated that if announced programmes in various countries are carried out, there should be an extra production of about $2 \frac{1}{4}$ million tons of nitrogen between June 1928 and June 1931. He calculates that, although 92 per cent of this could be absorbed by Europe alone if applied to main crops at the rate of $0.8 \mathrm{cwt}$. per acre, the additional world population in this period would not consume more than half of the extra food which would thus be available. On the other hand, Dr. Bueb, managing director of the Stickstoff Syndikat, has pointed out that the monetary return on the use of nitrogen has steadily risen, and the prices of foodstuffs have been kept down. The problem of production is subject to the economic laws, but co-operation between the forces concerned-those directed by the chemist, the engineer, the agriculturalist, and the plant breeder, is so full of economic possibilities that it would indeed be unwise to base our estimate of to-morrow's need solely on to-day's demand.

\section{Biology and Education. ${ }^{1}$}

\section{By Prof. F. A. E. Crew.}

$\mathrm{T}$ $\mathrm{HE}$ method of education is the stimulation of the cells of the brain by impressions from without: impressions provided by the casual and haphazard incidents of experience and by the deliberate and systematic agencies concerned with the imparting of facts and opinions. The aim of education is so to guide the development of the individual that he can hope to discover his powers, to recognise his limitations, and to determine the ways in which he may achieve the fullest degree of expression of his inherited mental and physical endowment in the circumstances, physical and social, in which he will find himself. Education, therefore, is concerned with the living individual and with the habitat in which this individual is to live and, living, achieve his destiny. So also is biology, the science which deals with the nature of living things and with the relation of these to their environment. It seeks to find answers to the questions as to whence came man, what is man, and

${ }^{1}$ From an address delivered before the Incorporated Association of Assistant Masters in Secondary Schcols at Brighton on Jan. 1. whither goeth he. These are the very questions that occupy the popular mind to-day. Surely the tasks of the educationist must be those of equipping his experimental material with the ability to formulate these questions properly and of showing how and where their answers may be found.

The most conspicuous factor in the history of civilisation during the last two hundred years has been the exploitation of physical Nature by means of scientific knowledge. Science has provoked and made possible a complete metamorphosis of the western world since the middle of the eighteenth century, and during this time science has been nurtured by industry. The Europeanisation of the world had its origins in the developments of commerce, and the broadening of the mental outlook which distinguished the Renaissance was made possible by the increased wealth and the increased leisure this commercial prosperity gave to western peoples. The industrial revolution in England was but the inevitable sequel of the developments of trade during the period $1600-1750$, and the present-

No. 3089, VoL. 123] 